\title{
Antiviral activity of Isatis indigotica root-derived clemastanin B against human and avian influenza $A$ and $B$ viruses in vitro
}

\author{
ZIFENG YANG $^{1,2^{*}}$, YUTAO WANG $^{2 *}$, ZHAOGUANG ZHENG $^{1}$, SUISHAN ZHAO $^{2}$,

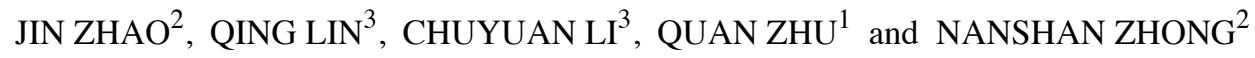 \\ ${ }^{1}$ Macau University of Science and Technology, Taipa, Macau, SAR; ${ }^{2}$ Clinical Virology Division, State Key Laboratory of \\ Respiratory Diseases, Guangzhou Medical University, The First Affiliated Hospital of Guangzhou Medical College, \\ Guangzhou; ${ }^{3}$ Hutchison Whampoa Guangzhou Baiyunshan Chinese Medicine Co., Guangzhou, P.R. China
}

Received October 10,2012; Accepted December 7, 2012

DOI: $10.3892 / \mathrm{ijmm} .2013 .1274$

\begin{abstract}
Clemastanin B, 7S,8R,8'R-(-)-lariciresinol-4,4'bis-O- $\beta$-D-glucopyranoside, is one of the major lignans extracted from Isatis indigotica root (IIR). In this study, the anti-influenza activities of clemastanin B were evaluated in vitro. Clemastanin B was found to inhibit different subtypes of human (H1N1, including swine-origin $\mathrm{H} 1 \mathrm{~N} 1$; $\mathrm{H} 3 \mathrm{~N} 2$ and influenza B) and avian influenza viruses (H6N2, $\mathrm{H} 7 \mathrm{~N} 3, \mathrm{H} 9 \mathrm{~N} 2)$ at different magnitudes of activity $\left(\mathrm{IC}_{50}\right.$ $0.087-0.72 \mathrm{mg} / \mathrm{ml}$ ) while this compound was inactive against respiratory syncytial virus (RSV), adenovirus 3 (ADV3), parainfluenza virus 3 (PIV3), enterovirus 71 (EV71) and human rhinovirus (HRV). An apparent virus titer reduction was detected when MDCK cells were treated with clemastanin B after viral infection, particularly at the early stage, and the ribonucleoprotein (RNP) of the influenza virus was retained in the nucleus after treatment with clemastanin $\mathrm{B}$. These results demonstrated that clemastanin $\mathrm{B}$ targets viral endocytosis, uncoating or RNP export from the nucleus. Furthermore, treatment with clemastanin B did not easily result in the emergence of viral drug resistance. The effects of clemastanin B demonstrated in this study may promote the antiviral study of IIR, but additional studies are required to define the anti-influenza mechanism(s).
\end{abstract}

Correspondence to: Professor Nanshan Zhong, State Key Laboratory of Respiratory Diseases, Guangzhou Medical College, The First Affiliated Hospital of Guangzhou Medical College, 1 Kangda Road, Guangzhou 510230, P.R. China

E-mail: nanshan@vip.163.com

Professor Quan Zhu, Macau University of Science and Technology, Taipa, Macau, SAR, P.R. China

E-mail: zhuquan1115@yahoo.com

*Contributed equally

Key words: influenza virus, clemastanin $\mathrm{B}$, in vitro, virus infection

\section{Introduction}

Influenza A viruses are a major cause of morbidity and mortality globally. The most severe pandemic human influenza outbreak occurred in 1918-1919, when the Spanish influenza caused more than 20 million deaths worldwide (1). In June 2009, the pandemic H1N1 virus spread rapidly throughout the world, and was characterized by a unique triple re-assortment of gene segments that had never before been identified in humans, pigs or birds (2). The rapid worldwide spread of the virus in less than two months led the WHO to raise the alert level of influenza pandemic from phase 3 to 6 (3). Although vaccination has been extremely successful in reducing the human cost of influenza virus infection, the search continues for effective therapeutic or prophylactic agents that may further diminish the threat of widespread outbreaks. Currently, adamantane derivatives (amantadine and rimantadine) and neuraminidase inhibitors (zanamivir and oseltamivir) are used for the prophylaxis and treatment of influenza $(4,5)$. However, viruses resistant to these drugs have emerged due to mutations at amino acid residues encoding the M2 ion channel or active sites of neuraminidase $(6,7)$. Another neuraminidase inhibitor, peramivir, has exhibited potent antiviral activity against influenza A and B viruses, and viral resistance has not been reported. Yet, due to the safety and overall experience, peramivir has not been approved by the FDA (8). For these reasons, alternative methods and therapies to prevent and overcome these obstacles have been suggested.

Isatis indigotica root (IIR, Radix isatidis), also known as Ban-Lan-Gen in Chinese, belongs to the family Cruciferae and is widely distributed in northern and central China. This medicinal plant has been traditionally used for the treatment of influenza, viral pneumonia, mumps, pharyngitis and hepatitis (9). Over the last decade, more than 50 chemical constituents have been identified in IIR. The antiviral compounds isolated from IIR including: $2,4(1 \mathrm{H}, 3 \mathrm{H})$-quinazolinedione (10), $(3 \mathrm{H})$-quinazolinone (11), lignan glycoside $\mathrm{A}, 8^{\prime} \mathrm{R}-(-)$-lariciresinol-4,4'-bis-O- $\beta$-Dglucopyranoside (clemastanin B), 5-hydroxymethylfurfural, 5-hydroxymethyl-furoic acid, epigoitrin $(12,13)$, banlangen polysaccharide (14), uridine, hypoxanthine, anthranilic acid, phenylformic acid and banlangen lectin (15). Among these, the antiviral monomers have received much attention, such as 
epigoitrin, 2,4(1H,3H)-quinazolinedione, 4(3H)-quinazolinone, clemastanin $\mathrm{B}$ and banlangen polysaccharide.

Clemastanin B was first isolated from the roots of Clematis stans by Kizu et al (16). Our research has focused on the antiviral effects of clemastanin B, which is one of the major lignans (content $0.04 \%$ ) extracted from IIR. Previously, He et al (17) reported that clemastanin B exhibited antioxidant bioactivities against free radicals, protected cells and inhibited HSV-1, HSV-2 in vitro; yet, its anti-influenza activity in vitro and the underlying mechanism have not been clarified to date in any published literature. The aim of the present study was to investigate the anti-influenza activities of clemastanin B in more detail against a variety of influenza strains (human and avian) in vitro and to evaluate its potency against the emergence of resistant strains in comparison with M2 inhibitors.

\section{Materials and methods}

Plant material, cells, reagents and viruses. IIR, cultivated in Good Agricultural Practice (GAP) farms in Fuyang, An-Hui Province, was obtained from Hutchison Whampoa Guangzhou Baiyunshan Chinese Medicine Co., Ltd. It was authenticated by Professor Ye Huagu at the Chinese Medicine Research Institute.

Madin-Darby canine kidney (MDCK), HEp-2, LLC-MK2, VERO-E6 and MRC-5 cells were purchased from the American Tissue Culture Collection (ATCC, Manassas, VA, USA). Influenza virus A/PR/8/34 (H1N1), A/FM/1/47 (H1N1), A/Aichi/2/68 (H3N2), parainfluenza virus 3 (PIV3) and respiratory syncytial virus (RSV, long strain) were purchased from ATCC and seasonal influenza virus A/Guangzhou/GIRD/02/09 (H1N1), B/Guangzhou/GIRD/08/09, novel swine influenza virus (A/Guangzhou/GIRD/07/09, H1N1, GenBank Accession no. HM014332.1), adenovirus type 3 (ADV3), enterovirus 71 (EV71) and human rhinovirus (HRV) were isolated from routine clinical specimens. Avian influenza strains of H6N2 (A/Duck/ Guangdong/2009), H7N3 (A/Duck/Guangdong/1994) and H9N2 (A/Chicken/Guangdong/1996) were a kind gift from Dr Jianxin Chen (South China Agricultural University). The influenza viruses were propagated and passaged in MDCK cells. HEp-2 cells were used as the host for RSV and ADV3. LLC-MK2 cells were used for culturing PIV3. VERO-E6 and MRC-5 cells were used to culture EV71 and HRV viruses. All cells were grown in Dulbecco's modified Eagle's medium (DMEM) with $10 \%$ heatinactivated fetal calf serum (FCS). D101 macroporous resin, $\mathrm{MCI}$ gel and Sephadex LH-20 were purchased from Beijing H\&E Co., Ltd. (Beijing, China).

Extraction and isolation of clemastanin B. Initially, $10 \mathrm{~kg}$ IIR were dried and ground to a power and extracted three times with 10 times water $(\mathrm{v} / \mathrm{w})$ for $2 \mathrm{~h}$. The extractions were combined and condensed to a proper volume under reduced pressure. Second, the solution was transferred to the D101 macroporous resin column and eluted with water, $10 \% \mathrm{EtOH}$ and $30 \% \mathrm{EtOH}$, respectively. Third, the $30 \% \mathrm{EtOH}$ elution was collected and condensed to a proper volume under reduced pressure, transferred to the MCI gel column and eluted with water, $10 \% \mathrm{MeOH}$ and $25 \% \mathrm{MeOH}$, respectively. Fourth, the $25 \% \mathrm{MeOH}$ elution was collected, condensed and dried under reduced pressure, dissolved in $\mathrm{MeOH}$ and purified using the
Sephadex LH-20 column. Finally, the material was crystallized with $\mathrm{MeOH}$ to produce a yellow-white power $(2.5 \mathrm{~g})$, which was identified as clemastanin B (Fig. 1).

Cytotoxicity assay. MDCK cells were left untreated or treated with the indicated amounts of clemastanin B. Cell viability was measured using the 3-(4,5-dimethylthiazol-2-yl)-3,5-diphenyltetrazolium bromide (MTT; GBC Bio Co., Ltd.) assay. Briefly, cells were treated with $5 \mathrm{mg} / \mathrm{ml}$ thiazole blue tetrazolium bromide in phosphate-buffered saline (PBS) and incubated for $3 \mathrm{~h}$ at $37^{\circ} \mathrm{C}$. The reaction product was dissolved in DMSO and cells were further incubated for $20 \mathrm{~min}$ at $37^{\circ} \mathrm{C}$. The absorbance was measured using a microplate reader at $570 \mathrm{~nm}(18)$.

Viral infections. For infection, cells were washed with PBS, incubated with virus diluted in serum-free MEM containing $100 \mathrm{U} / \mathrm{ml}$ penicillin and $0.1 \mathrm{mg} / \mathrm{ml}$ streptomycin for $1.5 \mathrm{~h}$ at $34^{\circ} \mathrm{C}$ at the indicated multiplicities of infection (MOI). The inoculums were aspirated, and the cells were incubated with MEM supplementing with $2 \mu \mathrm{g} / \mathrm{ml}$ TPCK-trypsin.

Treatment of viruses and cells with clemastanin B. MDCK cells $\left(0.8-1.0 \times 10^{5}\right)$ were seeded into each well of 12 -well plastic plates and cultured at $37^{\circ} \mathrm{C}$ for $24-48 \mathrm{~h}$. For the antiinfluenza activity assay and identification of the affected viral life cycle, cells were treated with clemastanin B using three different protocols (19-21) (Fig. 2). First, before viral adsorption, the cells were pre-incubated with clemastanin B for $2 \mathrm{~h}$ at $37^{\circ} \mathrm{C}$. The treated cells were then washed and inoculated with the virus (MOI, 0.01) for $2 \mathrm{~h}$ in the absence of clemastanin B and further cultured for 48-72 h. Second, cells were inoculated with the virus at $37^{\circ} \mathrm{C}$ for $2 \mathrm{~h}$, and then washed and cultured for 48-72 $\mathrm{h}$ in the presence of clemastanin B. Third, diluted clemastanin B was mixed with the virus and incubated at $37^{\circ} \mathrm{C}$ for $30 \mathrm{~min}$, and the mixture was added to the cells and further cultured for 48-72 h. The amount of progeny virus was determined using plaque assay crystal violet staining.

Time course assay (time-of-addition). MDCK cells in 24-well plates were prepared, then infected with virus (A/PR/8/34, $0.01 \mathrm{MOI})$ for $1 \mathrm{~h}$. After infection, the medium was discarded and cells were washed with PBS three times. Next, MEM was added to the cells, and incubation was carried out in $\mathrm{CO}_{2}$ incubator at $37^{\circ} \mathrm{C}$. Clemastanin $\mathrm{B}$ was added $1 \mathrm{~h}$ before infection, or at the same time with the virus or at indicated time points post-infection. At $12 \mathrm{~h}$ post-infection, the supernatants were collected and infectious titers were determined by plaque assay.

Activities against non-influenza viruses. The activities of clemastanin B against RSV (22), ADV (23), PIV3 (24), EV71 (25) and HRV (26) were evaluated. A total of 100 TCID $_{50}(50 \%$ tissue culture infective dose) of the viral infective titer was allowed to adsorb to the appropriate confluent cell lines for $2 \mathrm{~h}$, followed by washing of each virus with serum-free medium. Then, the test medium containing the desired concentration of clemastanin B was added. After appropriate periods of incubation, the cytopathic effect (CPE) in the virally infected cells was observed microscopically, and the $\mathrm{TCID}_{50}$ and the $50 \%$ inhibitory concentration $\left(\mathrm{IC}_{50}\right)$ were determined using methods described by Reed and Muench (27). 


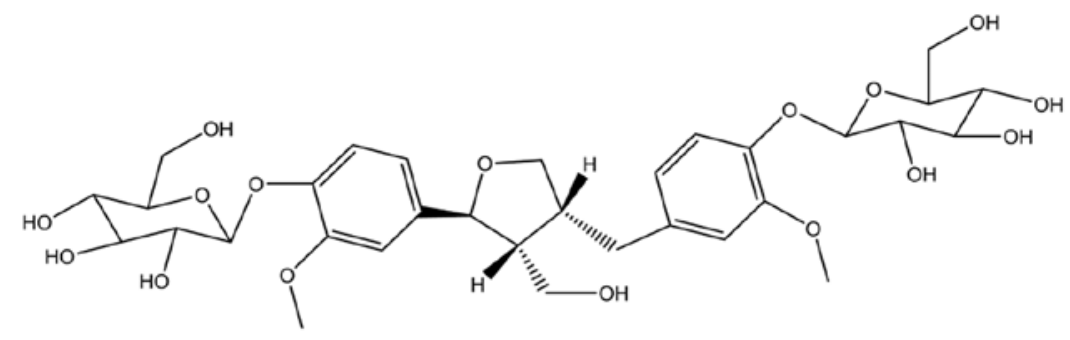

Figure 1. Chemical structure of clemastanin B.

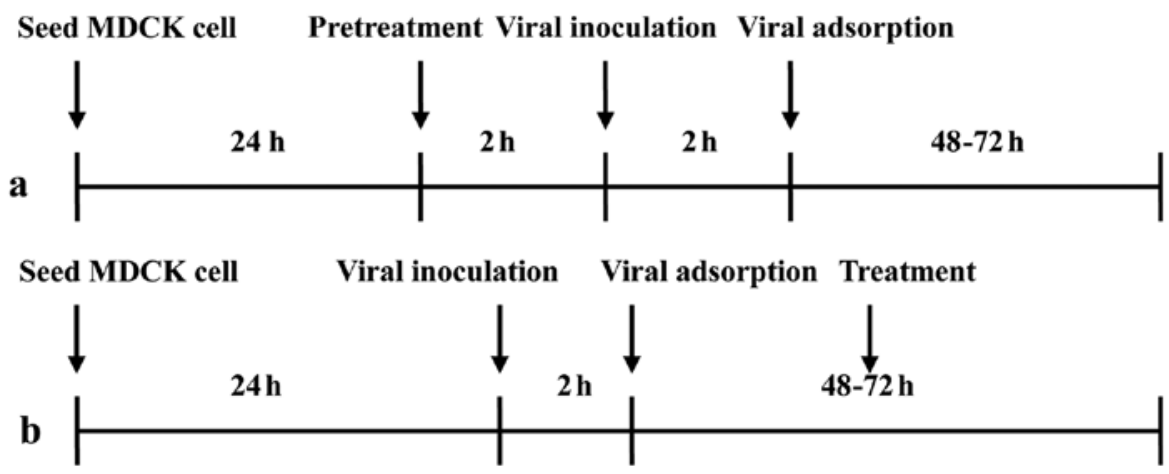

Drug and virus

Seed MDCK cell Direct reaction Viral inoculation Viral adsorption

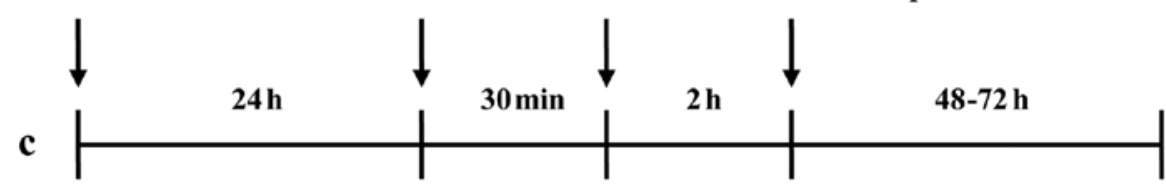

Figure 2. Three mode of treatment with clemastanin B. (a) Pre-treatment before viral adsorption; (b) treatment after viral adsorption; (c) drug and virus reaction before viral absorption.

Virus resistance assay. MDCK cells were infected with amantadine-sensitive influenza A virus (A/FM/1/47, 0.01 MOI) and left untreated or treated with clemastanin B $(1 \mathrm{mg} / \mathrm{ml})$, amantadine $(0.03 \mathrm{mg} / \mathrm{ml}$; Sigma-Aldrich) or ribavirin $(0.03 \mathrm{mg} / \mathrm{ml})$ for $24 \mathrm{~h}$. The post-infection supernatants were removed and used for infection in the second round of investigation. After infection, cells were left untreated or treated again with the indicated amount of clemastanin B or amantadine. This procedure was repeated six times. Supernatants were assayed for progeny virus yields by plaque assays. Virus yields of mocktreated cells were arbitrarily set as $100 \%$ (18).

Localization of influenza viral NP protein. MDCK cells $\left(0.8-1.0 \times 10^{5}\right)$ grown on glass coverslips were cultured at $37^{\circ} \mathrm{C}$ for 24-48 h, then infected with virus (A/PR/8/34, $1 \mathrm{MOI}$ ) for $2 \mathrm{~h}$. After infection, the medium was discarded and cells were washed with PBS three times. Next, clemastanin B was added to the cells and incubated in a $\mathrm{CO}_{2}$ incubator at $37^{\circ} \mathrm{C}$. At $8 \mathrm{~h}$ post-infection, cells were washed with PBS three times and fixed with $4 \%$ paraformaldehyde for $30 \mathrm{~min}$, and $1 \%$ Triton X-100 at room temperature. After blocking, fixed cells were incubated with NP-specific antibody (Santa Cruz Biotechnology, Inc.) overnight, washed with PBS three times, and cells were incubated with FITC-labeled goat anti-mouse antibody for $30 \mathrm{~min}$. Lastly, cells were incubated with DAPI (4',6-diamidino-2-phenylindole) DNA stain for $5 \mathrm{~min}$ and observed by fluorescence microscopy (28).

Statistical analysis. All experiments were carried out in triplicate and were representative of at least three separate experiments unless otherwise mentioned. Statistical significance of the data was determined by the one-way ANOVA method using SPSS 12.0 software. A P-value of $<0.05$ was considered to indicate a statistically significant result.

\section{Results}

Structural identification. The identification of the obtained materials was carried out by IR, MS, ${ }^{1} \mathrm{H}$ NMR and ${ }^{13} \mathrm{C}$ NMR spectra as follows. Yellow-white power, mp 201-202 ${ }^{\circ} \mathrm{C}$. IR $v^{\mathrm{KBr}} \mathrm{cm}^{-1}: 3401(\mathrm{OH}), 1261,1595,1510$. ESI-MS m/z: 707[M+Na] $]^{+}$, $1391[2 \mathrm{M}+1]^{+}$, ESI-MS $^{2}(m / z, 707) m / z: 545[\mathrm{M}+\mathrm{Na}-\mathrm{Glc}]^{+}, 361[\mathrm{M}-$ 2Glc $]^{+} .{ }^{1} \mathrm{H}$ NMR: (400 MHz, DMSO-d6+MeOD) $\delta: 7.195(1 \mathrm{H}$, d, $J=1.6 \mathrm{~Hz}, \mathrm{H}-2), 7.31$ (1H, d, J=8.4 Hz, H-5), 7.074 (1H, dd, $J=8.4,1.6 \mathrm{~Hz}, \mathrm{H}-6), 5.024(1 \mathrm{H}, \mathrm{d}, J=6.4 \mathrm{~Hz}, \mathrm{H}-7), 2.537(1 \mathrm{H}$, m, H-8), $7.102\left(1 \mathrm{H}, \mathrm{d}, J=1.6 \mathrm{~Hz}, \mathrm{H}-2^{\prime}\right), 7.289(1 \mathrm{H}, \mathrm{d}, J=8.4$, H-5'), 6.959 (1H, d, $\left.J=1.6 \mathrm{~Hz}, \mathrm{H}^{-} 7^{\prime} \alpha\right), 2.82(1 \mathrm{H}, \mathrm{dd}, J=11,3.8$, H-7' $), 2.791$ (1H, m, 8'-H), $4.05\left(9 \mathrm{H}, \mathrm{s}, 3 \mathrm{x}-\mathrm{OCH}_{3}\right), 5.089(1 \mathrm{H}$, 
Table I. Anti-influenza virus activities of clemastanin B, amantadine and ribavirin.

\begin{tabular}{lccccc}
\hline & \multicolumn{3}{c}{$\mathrm{IC}_{50}(\mathrm{mg} / \mathrm{ml})^{\mathrm{a}}$} \\
\cline { 2 - 6 } Virus type and strain & ${\text { Clemastanin } \mathrm{B}^{\mathrm{b}}}$ & ${\text { Clemastanin } \mathrm{B}^{\mathrm{c}}}$ & ${\text { Clemastanin } \mathrm{B}^{\mathrm{d}}}$ & Amantadine $^{\mathrm{c}}$ & Ribavirin $^{\mathrm{c}}$ \\
\hline $\mathrm{A} / \mathrm{PR} / 8 / 34$ (H1N1) & $>10$ & 0.32 & $>10$ & $>0.05$ & 0.037 \\
$\mathrm{~A} /$ FM/1/47 (H1N1) & $>10$ & 0.5 & $>10$ & 0.017 & 0.0068 \\
$\mathrm{~A} /$ Guangzhou/GIRD07/09 (H1N1) & $>10$ & 0.087 & $>10$ & $>0.05$ & 0.012 \\
A/Guangzhou/GIRD02/2009 (H1N1) & $>10$ & 0.27 & $>10$ & $>0.05$ & 0.013 \\
A/Aichi/2/68 (H3N2) & $>10$ & 0.62 & $>10$ & 0.015 & 0.021 \\
A/Duck/Guangdong/2009 (H6N2) & $>10$ & 0.37 & $>10$ & 0.015 & 0.009 \\
A/Duck/Guangdong/1994 (H7N3) & $>10$ & 0.088 & $>10$ & 0.025 & 0.014 \\
A/Chicken/Guangdong/1996 (H9N2) & $>10$ & 0.171 & $>10$ & $>0.05$ & 0.021 \\
B/Guangzhou/GIRD08/09 & $>10$ & 0.72 & $>10$ & $>0.05$ & 0.021 \\
\hline
\end{tabular}

${ }^{\mathrm{a}}$ Mean of results from two or three independent experiments. ${ }^{\mathrm{b}}$ Treatment before viral adsorption; ${ }^{\mathrm{c}}$ treatment after viral adsorption; ${ }^{\mathrm{d}} \mathrm{drug}$ and viral reaction before viral absorption.

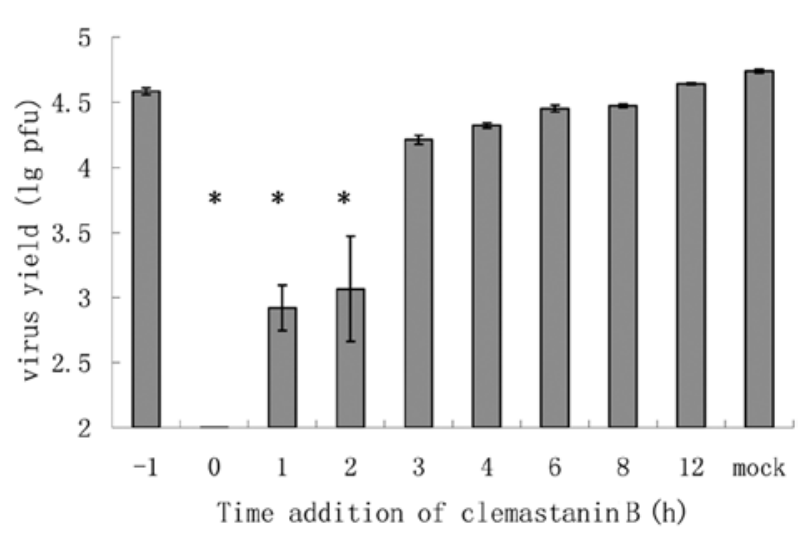

Figure 3. MDCK cells were infected with virus (A/PR/8/34, $0.01 \mathrm{MOI})$ for $1 \mathrm{~h}$. After infection, the medium was discarded and cells were washed with PBS. MEM was then added to the cells and incubated in a $\mathrm{CO}_{2}$ incubator at $37^{\circ} \mathrm{C}$. Clemastanin $\mathrm{B}$ was added $1 \mathrm{~h}$ before infection and then again at 0,1 , $2,3,4,5,6,8$ and 10 after infection. At $12 \mathrm{~h}$ after infection the supernatants were collected and infectious titers were determined by a plaque reduction assay. The mean difference is significant $\left({ }^{*} \mathrm{P}<0.01\right)$

d, J=7.6 Hz, H-1"), $5.122\left(1 \mathrm{H}, \mathrm{d}, J=7.6 \mathrm{~Hz}, \mathrm{H}-1^{\prime \prime \prime}\right) .{ }^{13} \mathrm{C}$ NMR: (125 MHz, DMSO-d6+MeOD) $\delta: 136.88(\mathrm{C}-1), 111.46(\mathrm{C}-2)$, 150.70 (C-3), 147.18 (C-4), 117.41 (C-5), 119.49 (C-6), 83.56 (C-7), 54.09 (C-8), 60.37 (C-9), 136.88 (C-1'), 114.39 (C-2'), 150.69 (C-3'), 117.72 (C-5'), 122.12 (C-6'), 33.63 (C-7'), $43.64\left(\mathrm{C}-8^{\prime}\right), 73.53\left(\mathrm{C}-9^{\prime}\right), 56.77\left(\mathrm{OCH}_{3}\right), 102.59\left(\mathrm{C}-1^{\prime \prime}\right)$, 74.87 (C-2"), 56.77 (C-3"), 71.27 (C-4"), 78.26 (C-5"), 62.37 (C-6"), 102.45 (C-1"'), 74.87 (C-2'"), 56.77 (C-3"'), 71.27 (C-4"'), 77.99 (C-5"'), 62.37 (C-6"'). These data were consistent with the literature $(16,29)$. The purity was $>98 \%$, as determined by HPLC analysis.

Cytotoxicity. Clemastanin B was tested for cytotoxicity against MDCK, HEp-2, LLC-MK2, VERO-E6 and MRC-5 cells. The MTT data indicated that clemastanin B did not negatively affect the viability of the cells. The $\mathrm{TC}_{50}$ of MDCK, HEp-2, LLC-MK2, VERO-E6 and MRC-5 cells was 7.5, 6.2, 7.5, 6.3, 7.5 and $7.5 \mathrm{mg} / \mathrm{ml}$, respectively.

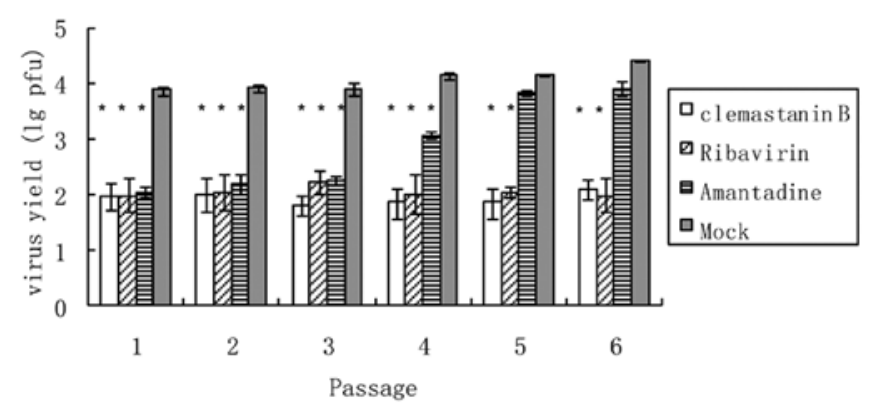

Figure 4. MDCK cells were infected with influenza A virus (FM1, 0.01 MOI) and were left untreated or treated with the drugs $(1 \mathrm{mg} / \mathrm{ml}$ clemastanin $\mathrm{B}$, $0.03 \mathrm{mg} / \mathrm{ml}$ ribavirin, $0.03 \mathrm{mg} / \mathrm{ml}$ amantadine). At $48 \mathrm{~h}$ post-infection, supernatants were removed and MCDK cells were infected for the second time. After infection the cells were left untreated or treated with the drugs. This procedure was repeated six times. The supernatants were assayed for progeny virus by plaque titration. The mean difference is significant $\left({ }^{*} \mathrm{P}<0.01\right)$.

Anti-influenza activity of clemastanin B. Clemastanin B was tested using a plaque assay for inhibition against a series of human and avian influenza viruses at different magnitudes of activity. The mode of action of clemastanin B was studied. When MDCK cell lines were pre-treated with clemastanin B before viral adsorption or with the influenza virus pre-incubated with clemastanin B, no protective effect was observed (Table I). However, when MDCK cell lines were treated with clemastanin B after virus incubation, a pronounced titer reduction of progeny virus was detected.

Time course assay (time-of-addition) in influenza virusinfected cells. The antiviral mechanism of clemastanin B was determined by a time course assay in a single infectious cycle using an A/PR/8/34 (H1N1) infection model. A notable and significant reduction was observed when clemastanin $\mathrm{B}$ was applied between 0 and $2 \mathrm{~h}$ after viral adsorption, which indicated that clemastanin $\mathrm{B}$ targets the early viral replication 
anti-NP

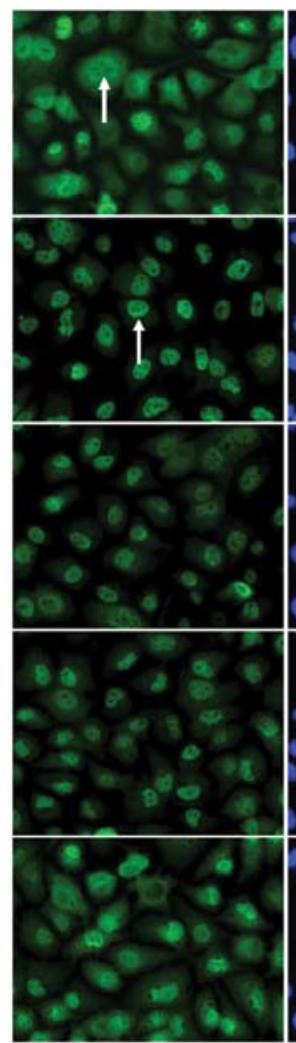

DAPI

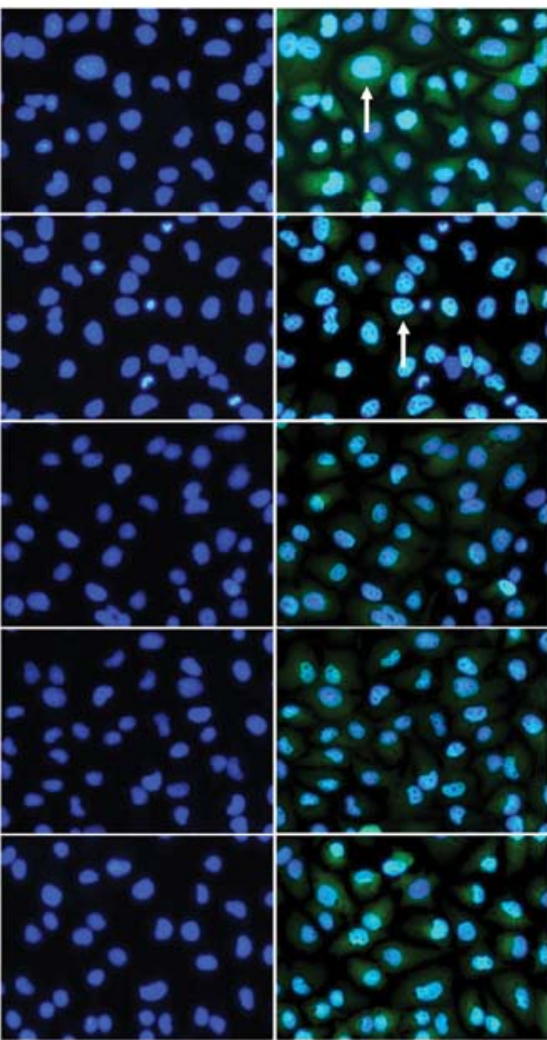

MERGE

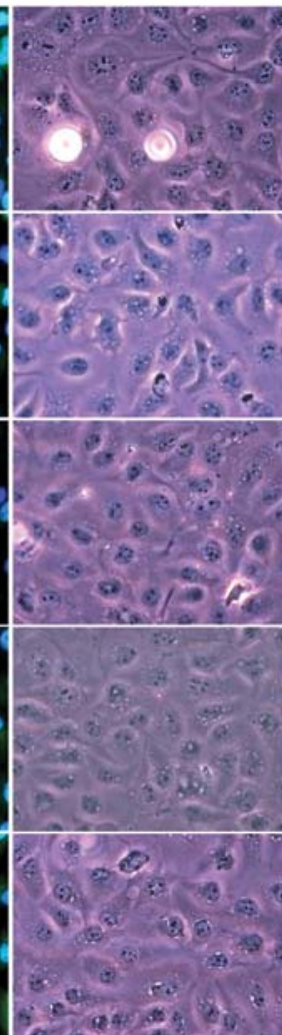

no treatment

$0.4 \mathrm{mg} / \mathrm{ml}$

$0.2 \mathrm{mg} / \mathrm{ml}$

$0.1 \mathrm{mg} / \mathrm{ml}$

$0.05 \mathrm{mg} / \mathrm{ml}$

Figure 5. Intracellular localization of viral NP. MDCK cells were infected with virus (A/PR/8/34, $1 \mathrm{MOI})$ in the absence and at different concentrations of clemastanin B for $8 \mathrm{~h}$. Cells were observed by fluorescence microscopy using NP-specific antibody. The cells were also stained with DNA labeling dye DAPI. The merger showed that the intracellular DNA and the RNPs co-localized within the nucleus. Cytoplasmic localization of viral RNPs (NP, green) and of selected nuclei (DAPI, blue) is indicated (white arrows).

stage rather than adsorption or late stage of viral replication (Fig. 3).

Spectrum of antiviral activity. The spectrum of antiviral activity of clemastanin B was investigated. It did not inhibit the CPE caused by RSV, ADV, PIV3, EV71, and the HRV IC 50 values in all cases were $>10 \mathrm{mg} / \mathrm{ml}$.

Tendency to induce viral resistance. A multi-passage experiment to detect the emergence of resistant viruses in cell culture was set up as a reference (30). Virus titers from cells treated with amantadine were at the same levels as untreated cells after five passages, showing that this pool of viruses had become fully resistant to the drug (Fig. 4). This was different from infected cells treated with clemastanin B, where viral titers did not rise with increasing passage numbers, indicating that the influenza virus was not resistant to clemastanin B.

Clemastanin $B$ treatment results in NP distribution in the nuclei. The viral NP produced by influenza A/PR/8/34 was evident and its expression persisted thereafter. NP was distributed not only in the cytoplasm but also in the nuclei of the infected cells (Fig. 5). However, in the clemastanin B-treated cells, the results showed that NP production was only distributed in the nuclei of the infected cells.

\section{Discussion}

The Chinese herbal medicine, Isatis indigotica root, has been traditionally known to have an effect on fever and sore throats. Many chemical compounds have been isolated from IIR, including indigotin, indirubin, tryptanthrin, isatin, isaindigotidione, epigoitrin, 2,4(1H,3H)-quinazolinedione, clemastanin B, 4(3H)-quinazolinone and others. Among them, tryptanthrin, indigo and indirubin are usually selected as markers for quality control due to their unique pharmaceutical activities. Indirubin has been shown to have potent anti-influenza viral activities by inhibition of RANTES (also known as CCL5) expression (31). Yamada (32) previously reported a glycoprotein from Radix isatidis that showed useful antiviral activities in the therapy and prevention of viral infection in vitro and in vivo. Clemastanin $\mathrm{B}$, a major lignan in IIR, has been isolated using conventional methods. However, evidence of the inhibition of influenza virus by clemastanin $B$ from IIR has not been previously reported and its mode of action remains elusive.

Herein, we found that clemastanin B showed inhibitory effects against different subtypes of human or avian influenza viruses at different magnitudes of activity in vitro. Among these, clemastanin B inhibited the swine-origin $\mathrm{H} 1 \mathrm{~N} 1$ and avian influenza virus $\mathrm{H} 7 \mathrm{~N} 3$ with an $\mathrm{IC}_{50}$ of 0.087 and $0.088 \mathrm{mg} / \mathrm{ml}$, respectively, indicating potent effects against 
such pathogens. Further investigations are required to determine this specificity.

In contrast, clemastanin B showed no antiviral activity against RSV, PIV3, ADV3, EV71 and HRV. These results suggest that clemastanin B exhibits a broad range and selective antiviral activity against various subtypes of influenza viruses. However, previous reports had shown that clemastanin B had antiviral activity against HSV-1 and HSV-2 in vitro, but no such activities resulted from our experimentation. These contradictory results may be due to different assays or specificity to strains.

Generally, the influenza virus replication cycle can be divided into six steps: adsorption, endocytosis, uncoating, packaging, budding and release (33). To determine at which step clemastanin B acts in the viral life cycle, its mode of action was observed. Pretreatment of cells following viral infection or at late stages of viral infection did not affect viral replication. This indicated that the viral adsorption, budding or release were not affected by clemastanin B. Our results also revealed that clemastanin $B$ did not inhibit the influenza virus hemagglutinin specificity as determined by the hemagglutinin inhibition assay and the NA protein by NA inhibition (data not shown). Clemastanin B displayed antiviral properties when the virus and drugs were added to cells simultaneously, as well as post-infection, particularly in the early replication stage. These results suggest that an early stage of viral replication, for exampe endocytosis or uncoating, were inhibited. In addition, the RNP remained in the nucleus of clemastanin B-treated cells, which suggests that clemastanin B may interfere with RNP export from the nucleus at an early stage and persists throughout the rest of the infection. It was reported that there were several cell signaling pathways related to RNP export: Raf/MEK/ERK signaling (34), PKC $\alpha$ (35), PI3/akt (36) and NF- $\kappa \mathrm{B}$ pathways (37). These pathways influence the expression of cytokines and chemokines. The Raf/MEK/ERK signaling pathway induced by influenza virus is essential for viral RNP export. Thus, we cannot exclude the possibility that clemastanin B may effect these pathways.

It has been reported that amino adamantine-resistant viruses readily emerge and were already prevalent worldwide during the recent seasonal $\mathrm{H} 1 \mathrm{~N} 1$ and $\mathrm{H} 3 \mathrm{~N} 2$ influenza pandemics $(38,39)$. The swine-origin H1N1 pandemic in 2009 was already amino adamantine-resistant (40). This feature was also replicated in our in vitro study, as the viruses in the presence of amantadine were resistant to amantadine at passage five, while the viruses passaged in the presence of clemastanin B did not result in the emergence of viral drug resistance until the sixth passage. These results demonstrated that clemastanin B did not easily result in the emergence of viral drug resistance in vitro and may possess unique mechanisms against influenza viruses that are different from the existing antiviral drugs such as M2 or neuraminidase inhibitors. To our knowledge, this is the first report showing that clemastanin B has antiviral effects against various influenza $A$ and $B$ viruses.

Given that its probable mechanism of action differs from current antiviral agents and it is derived from a common TCM medicinal plant, clemastanin B could be developed as a moderate antiviral drug candidate via inhibition of viral replication after infection, particularly in the early replication stage, although it was not a very potent antiviral compound when compared with ribavirin or amantadine.

Additionally, clemastanin B did not easily result in drug resistance compared with M2 inhibitors. The effects of clemastanin B illustrated in this study promote the antiviral study of IIR. However, additional studies are required to define the anti-influenza mechanism(s).

\section{Acknowledgements}

This work was funded by the National Science and Technology Major Project of the Ministry of Science and Technology of China (Grant no. 2013ZX09201021, 2013ZX09304102), the National Natural Science Foundation of China (Grant no. U1201227), Guangdong Natural Science Foundation (Grant no. S2012010008276), the Joint Research foundation of Department of Education, Guangdong Province (Grants no. gxzd0901), Guangzhou Science and Technology Project (Grants no.2011Y3-00039), the Science and Technology Development Fund in Macao Special Administrative Region (Grant no. 043/2007/A3), Recruitment Project of Guangzhou Technology Bureau for enterprises scientific and technological problems (Grant no. 2008Z1-I011). The funders had no role in study design, data collection and analysis, decision to publish, or preparation of the manuscript.

\section{References}

1. Nicholson KG, Wood JM and Zambon M: Influenza. Lancet 362: 1733-1745, 2003.

2. Trifonov V, Khiabanian H, Greenbaum B and Rabadan R: The origin of the recent swine influenza seasonal influenza A(H1N1) virus infecting humans. Euro Surveill 14: 19193, 2009.

3. Centers for Disease Control and Prevention (CDC): Update: Infections with a Swine-Origin Influenza A (H1N1) Virus, United States and other countries, 2009. http://www.cdc.gov/ mmwr.

4. Hayden FG and Hay AJ: Emergence and transmission of influenza A viruses resistant to amantadine and rimantadine. Curr Top Microbiol Immunol 176: 119-130, 1992.

5. de Jong MD, Tran TT, Truong HK, Vo MH, Smith GJ, Nguyen VC Bach VC, Phan TQ, Do QH, Guan Y, Peiris JS, Tran TH and Farrar J: Oseltamivir resistance during treatment of influenza A (H5N1) infection. N Engl J Med 353: 2667-2672, 2005.

6. Deyde VM, Xu X, Bright RA, Shaw M, Smith CB, Zhang Y, Shu Y, Gubareva LV, Cox NJ and Klimov AI: Surveillance of resistance to adamantanes among influenza $\mathrm{A}(\mathrm{H} 3 \mathrm{~N} 2)$ and $\mathrm{A}(\mathrm{H} 1 \mathrm{~N} 1)$ viruses isolated worldwide. J Infect Dis 196: 249-257, 2007.

7. Le QM, Kiso M, Someya K, Sakai YT, Nguyen TH, Nguyen KH, Pham ND, Ngyen HH, Yamada S, Muramoto Y, Horimoto T, Takada A, Goto H, Suzuki T, Suzuki Y and Kawaoka Y: Avian flu: isolation of drug-resistant H5N1 virus. Nature 437: 1108, 2005.

8. Shetty AK and Peek LA: Peramivir for the treatment of influenza. Expert Rev Anti Infect Ther 10: 123-143, 2012.

9. Chang YS and Ho YL: Studies on the homonymic Chinese crude drug species in Taiwan. Evaluation of the quality of DA-Ching-Yeh and Ching-Dai. Anal Sci 17: a423-a426, 2001.

10. Xu LH, Huang F, Cheng T and Wu J: Antivirus constituents of radix of Isatis indigotica. Chin J Nat Med 3: 359-361, 2005.

11. Li L, Dong TY, Li XL and Qiao CZ: Study of quality control on herbal drugs and preparations of daqingye and banlangen. Acta Pharm Sin 28: 229-233, 1993 (In Chinese).

12. Huang QS, Yoshihiro K and Natori S: Isolation of 2-hydroxy -3-butenyl thiocyanate, epigoitrin and adenosine from 'banlangen', Isatis indigotica root. Planta Med 42: 308-310, 1981.

13. Li X, He LW and Sun DD: The methods of anti-virus extract from Radix and its use. P: CN1969923, 05-30, 2007. 
14. Zuo Y, Dai M, Wang ZY and Liu J: Effects of banlangen polysaccharide on mice resistance to Influenza virus infection. WCJ PS 23: 666-667, 2008.

15. An YQ, Jia XB, Yuan HJ, Chen Y and Jin XY: Thinking in studies on antiviral material base of Radix isatidis. Chin Tradit Herbal Drugs 39: 616-619, 2008.

16. Kizu H, Shimana H and Tomimori T: Studies on the constituents of clematis species. VI. The Constituents of Clematis stans Sieb. et Zucc. Chem Pharm Bull 43: 2187-2194, 1995.

17. He LW, LI X, Chen JW, Xia Y and Wang YY: Determination of lariciresinol-4,4'-bis-O-b-D-glucopyranoside from Radix isatidis by HPLC. Chin Tradit Herbal Drugs 39: 1895-1897, 2008.

18. Ehrhardt C, Hrincius ER, Korte V, Mazur I, Droebner K, Poetter A, Dreschers S, Schmolke M, Planz O and Ludwig S: A polyphenol rich plant extract, CYSTUS052, exerts anti-influenza virus activity in cell culture without toxic side effects or the tendency to induce viral resistance. Antiviral Res 76: 38-47, 2007.

19. Yingsakmongkon S, Miyamoto D, Sriwilaijaroen N, Fujita K Matsumoto K, Jampangern W, Hiramatsu H, Guo CT, Sawada T, Takahashi T, Hidari K, Suzuki, T, Ito M, Ito Y and Suzuki Y: In vitro inhibition of human influenza A virus infection by fruit-juice concentrate of Japanese plum (Prunus mume SIEB. et ZUCC). Biol Pharm Bull 31: 511-515, 2008

20. Miyamoto D, Hasegawa S, Sriwilaijaroen N, Yingsakmongkon S, Hiramatsu H, Takahashi T, Hidari K, Guo CT, Sakano Y, Suzuki T and Suzuki Y: Clarithromycin inhibits progeny virus production from human influenza virus-infected host cells. Biol Pharm Bull 31: 217-222, 2008.

21. Knox YM, Suzutani T, Yosida I and Azuma M: Anti-influenza virus activity of crude extract of Ribes nigrum L. Phytother Res 17: 120-122, 2003.

22. Graham BS, Perkins MD, Wright PF and Karzon DT: Primary respiratory syncytial virus infection in mice. J Med Virol 26 153-162, 1998

23. Hui MB, Lien EJ and Trousdale MD: Inhibition of human adenoviruses by 1-(2'-hydroxy-5'-methoxybenzylidene) amino3-hydroxyguanidine tosylate. Antiviral Res 24: 261-273, 1994.

24. Mao H, Thakur CS, Chattopadhyay S, Silverman RH, Gudkov A and Banerjee AK: Inhibition of human parainfluenza virus type 3 infection by novel small molecules. Antiviral Res 77: 83-94, 2008

25. Ho HY, Cheng ML, Weng SF, Leu YL and Chiu DT: Antiviral effect of epigallocatechin gallate on enterovirus 71. J Agric Food Chem 57: 6140-6147, 2009.

26. Kaiser L, Crump CE and Hayden FG: In vitro activity of pleconaril and AG7088 against selected serotypes and clinical isolates of human rhinoviruses. Antiviral Res 7: 215-220, 2000.

27. Reed LJ and Muench H: A simple method of estimating fifty percent endpoints. Am J Hyg 27: 493-497, 1938.
28. Ludwig S, Wolff T, Ehrhardt C, Wurzer WJ, Reinhardt J, Planz O and Pleschka S: MEK inhibition impairs influenza B virus propagation without emergence of resistant variants. FEBS Lett 561: 37-43, 2004

29. Peng JP, Fan GR and Wu YT: Isolation and purification of clemastanin B and indigoticoside A from Radix isatidis by highspeed counter-current chromatography. J Chromatogr A 1091: 89-93, 2005.

30. Taubenberger JK: The origin and virulence of the 1918 'Spanish' influenza virus. Proc Am Philos Soc 150: 86-112, 2006.

31. Mak NK, Leung CY, Wei XY, Shen XL, Wong RN, Leung KN and Fung MC: Inhibition of RANTES expression by indirubin in influenza virus-infected human bronchial epithelial cells. Biochem Pharmacol 67: 167-174, 2004.

32. Yamada $\mathrm{H}$ : Antiviral compositions containing new glycoprotein from Isatis tinctoria. Acta Pharm Sin 1160: 599, 1999.

33. Palese P: Influenza: old and new threats. Nat Med 10 (Suppl 12): S82-S87, 2004

34. Pleschka S, Wolff T, Ehrhardt C, Hobom G, Planz O, Rapp UR and Ludwig S: Influenza virus propagation is impaired by inhibition of the Raf/MEK/ERK signalling cascade. Nat Cell Biol 3: 301-305, 2001.

35. Marjuki H, Alam MI, Ehrhardt C, Wagner R, Planz O, Klenk HD, Ludwig S and Pleschka S: Membrane accumulation of influenza A virus hemagglutinin triggers nuclear export of the viral genome via protein kinase Calpha-mediated activation of ERK signaling. J Biol Chem 81: 16707-16715, 2006.

36. Wu MS, Yen HR, Chang CW, Peng TY, Hsieh CF, Chen CJ, Lin TY and Horng JT: Mechanism of action of the suppression of influenza virus replication by Ko-Ken Tang through inhibition of the phosphatidylinositol 3-kinase/Akt signaling pathway and viral RNP nuclear export. J Ethnopharmacol 134: 614-623, 2011.

37. Mazur I, Wurzer WJ, Ehrhardt C, Pleschka S, Puthavathana P, Silberzahn T, Wolff T, Planz O and Ludwig S: Acetylsalicylic acid (ASA) blocks influenza virus propagation via its NF-kappaBinhibiting activity. Cell Microbiol 9: 1683-1694, 2007.

38. Bright RA, Medina MJ, Xu X, Perez-Oronoz G, Wallis TR, Davis XM, Povinelli L, Cox NJ and Klimov AI: Incidence of adamantane resistance among influenza A (H3N2) viruses isolated worldwide from 1994 to 2005: a cause for concern. Lancet 366: 1175-1181, 2005.

39. Bright RA, Shay DK, Shu B, Cox NJ and Klimov AI: Adamantane resistance among influenza A viruses isolated early during the 2005-2006 influenza season in the United States. JAMA 295 891-894, 2006.

40. Dawood FS, Jain S, Finelli L, Shaw MW, Lindstrom S, Garten RJ, Gubareva LV, Xu X, Bridges CB and Uyeki TM: Emergence of a novel swine-origin influenza A (H1N1) virus in humans. N Engl J Med 360: 2605-2615, 2009. 